\title{
The Systems Metaphor in Therapy Discourse: Introducing Systems Intelligence
}

Frank Martela, M.Sc., and Esa Saarinen, Ph.D.

Frank Martela, M.Sc. (Soc. Sci.), M.Sc. (Eng.), is a Researcher at Aalto University, Unit of Work Psychology and Leadership. Esa Saarinen, Ph. D., is Professor at Aalto University, Unit of Work Psychology and Leadership, and Docent at Helsinki University, Department of Philosophy. We are grateful to Alfred Colliander, Raimo P. Hämäläinen, Peter Kenttä, Jukka Luoma, Mike Manning, Ian Marson, Jeremy Nahum, Robert Seligman, Robert Stolorow, James Wilk and the anonymous referees of Psychoanalytic Dialogues for encouragement and helpful comments on earlier drafts of this paper. 


\section{Abstract:}

Following the relational turn in psychoanalytic theorizing, the systems metaphor has increasingly become a part of the therapeutic vocabulary. This has led to a view of therapy as an ongoing process in which the mutual interplay between the analyst and the patient cocreates a systemic higher-level dimension that is based on bidirectional and jointly coordinated, simultaneous forms of interaction that influence the mental processes and regulatory patterns of both of the participants thus creating possibilities for creative therapeutic interventions. However, the objectivistic overtones of the systems metaphor can lead to reifying interpretations of the therapeutic encounter and to a failure to acknowledge its intrinsically subtle context-bound nuances and often idiosyncratic possibilities. This pitfall is avoided by introducing into therapeutic discourse the concept of systems intelligence which integrates systems thinking with subjectivistic and intersubjectivistic parameters. By emphasizing the analyst's embeddedness within the systemic wholeness of the therapeutic situation and her sensibilities-based abilities to act intelligently in it, systems intelligence provides a humanly tuned meta-understanding for the systemic aspects of the therapist in action. 


\section{Therapy}

"Analytic therapists tolerate uncertainty, find meaning in apparently disordered communication, and embrace the unexpected twists and turns that emerge from intimate attention to the ordinary complexities of everyday life. These are hallmarks of a psychoanalytic sensibility that spans various theoretical persuasions. Non-linear dynamic systems embodies the same sensibilities: It emphasizes such descriptions as pattern, complexity, flux and flow, the interplay of ambiguity and order, stability and instability, and the natural value of uncertainty and generative chaos" (Seligman, 2005, p. 285)

\section{Introduction}

As the relational turn has swept through psychoanalytic theorizing, the systems metaphor has increasingly become a part of the therapeutic vocabulary. In recent decades psychoanalysis has increasingly moved away from the classical Cartesian isolated minds and from the related “objectivist, technically rational stance" (Hoffman, 2001, p. xii) towards a more relational (Beebe \& Lachmann, 2003; Mitchell, 1988) and 
intersubjective (Dunn, 1995; Marzi, Hautmann, \& Maestro, 2006; Stolorow, Atwood, \& Orange, 2002) understanding of the therapeutic situation. The development goes by many names: "the relational turn" (Beebe $\&$ Lachmann, 2003; Mitchell, 1988), "intersubjectivity" (Dunn, 1995; Marzi et al., 2006), "postmodern perspective" (Goldberg, 2001; Rabin, 1995) and “intersubjectivist-relational turn” (Seligman, 2005, p. 316) but irrespective of the name, the movement has grown to be a prominent force within psychoanalysis. The relational perspective has highlighted dimensions of the analytic field previously neglected, such as "ambiguity, complexity, epistemological uncertainty, multiperspectivism, and an interest in coconstruction and evolving process." (Seligman, 2005, p. 316). Regarding therapeutic practice, these approaches are advocating a more empathic, attuned and humane way of interrelating with patients instead of an attitude of intellectual disattachment.

An important parallel development is one that conceives of the therapeutic situation as a system. Generally speaking, a systems approach looks at the therapeutic situation as a dyadic system within which both intrapsychic and interpsychic processes take place (Beebe, Knoblauch, Rustin, \& Sorter, 2003; Stolorow, 1997). The roots of systems perspective are in the general systems theory of von Bertalanffy (1968) but it is mainly through Louis Sander's $(1977,1985,1995)$ work in infant research and through the dynamic systems approach to development of Thelen and Smith (1994, p. xiii) that the systems view has found its way into psychoanalysis (see Beebe et al., 2000; Nahum, 2000; Sander, 2002; 


\section{Therapy}

Seligman, 2005; Stolorow, 1997) ${ }^{1}$. Important contributors in this development towards a new way to think about "psychoanalytic metapsychology" (Seligman, 2005, p. 287) have included - among others - the works of Stolorow (1997), Sander (2002), Seligman (2005), Beebe and Lachmann (2005), the work of the Boston Change Process Study Group [hereafter, the Boston Group] $(2002,2007,2010)$ and the contributions of Galatzer-Levy (2004, 2009a, 2009b). According to Seligman (2005, p. 287) “most contemporary analysts now think of analyst and analysand immersed in ongoing, complex patterns of mutual influence; whatever other assumptions they make, they agree that a psychoanalysis is a dyadic and dynamic system."2

One of the key advantages of the systems perspective is that it offers a language that captures many of the implicit key assumptions of clinical practice. At the same time it has been welcomed for providing a scientific backing for the relational perspective (Galatzer-Levy, 2009b; Seligman, 2005). Accordingly, this coming together of relational perspective and systems theory has been described as "a marriage made in heaven" (Harris, 2009, p. 5). But if systems perspective provides the new metalevel understanding of the nature of the psychoanalysis, we need a way to understand what the systems concept means in this context. Given the scientific and objectival paradigm from which the systems concept has emerged, this is a pertinent issue. To wit, there is an unmistakable tension

\footnotetext{
${ }^{1}$ For an overview of the development of the field see Galatzer-Levy (2009a).

${ }^{2}$ Similarly, Stolorow et al. (2002, p. 33) state that "most contemporary psychoanalytic schools emphasize relatedness, dialogue, and even systems theory."
} 
between the sensitive ways the analysts are using the systems perspective and the objectival overtones of the systems concept as it is articulated in systems theories (for overviews, see Jackson, 2003; Ramage \& Shipp, 2009). We will argue that this tension is the source of many of the misplaced criticisms laid upon the therapeutic writers using systems vocabulary. As the chief contribution of this paper we suggest that the concept of systems intelligence provides a way of bridging the gap between the rich relational understanding of the therapeutic practice and the objectival overtones of the systems perspective. Our thesis is that the concept of systems intelligence can significantly further the metatheoretical understanding of the therapy process in its fundamentally elusive, context-bound, relational, emergent and systems dynamic nature.

\section{Systems perspective in psychoanalysis}

When applied to the psychoanalysis, dynamic systems theory seeks to account for the "messy, fluid, context-sensitive" (Thelen \& Smith, 1994, p. $\mathrm{xvi)}$ nature of the therapeutic process through employing concepts from systems theories, such as complexity, non-linearity, self-organization, dynamic stability, softly assembled patterns and bi-directional interaction (Beebe et al., 2000; Coburn, 2002; Stolorow, 1997; Thelen, 2005). The systems perspective rejects the conceptualization of the analyst and the patient as separate identifiable units with distinct characteristics that exist independently of the therapeutic context. Development and the success of a therapy are viewed as the "outcome of the self-organizing processes of continuously active living systems" (Thelen \& Smith, 1994, p. 44). 


\section{Therapy}

Stable intrapsychic patterns are replaced by a highly contextualized view of individual subjectivity in which "worlds of inner experience and intersubjective fields mutually constitute one another" (Stolorow, 1997, p. 339) and where the therapist's actions are embedded in the ongoing living system formed by the "mutual regulatory process" between the patient and the analyst (Nahum, 2000, p. 39). Order should be viewed as growing out of states of dynamic stability that are "emergent and not designed" (Thelen \& Smith, 1994, p. xix).

Undoubtedly, one reason for the continued enthusiasm for the systems perspective in psychoanalytic meta-understanding is the possibility of connecting to a scientifically rigorous vocabulary that promises to provide an enriched framework for the complexities of the actual therapeutic situation. The effort towards making psychoanalysis an exact science has been a dominant force for a long time (Rabin, 1995, p. 468; Mitchell, 1988), but more recently it has been challenged by theorists and practitioners of psychoanalysis on the ground that scientific rigor easily downplays the abundant richness of the actual therapeutic encounter (Orange, Atwood, \& Stolorow, 1997, p. 19). In this context, systems theories offer a link to the natural sciences in ways that "do not drag analysis away from its most imaginative virtues" (Seligman, 2005, p. 287).

One way in which the systems approach has been beneficial is in serving a practicing therapist as a "source of guiding metaphors" (Stolorow, 1997, p. 337). An analyst can approach nonlinear system dynamics in an “intuitive, experience-near way so as to offer a language and an imagery 
that captures many of the basic assumptions that underlie our everyday clinical thinking, interacting and experiencing" (Seligman, 2005, p. 286). Introducing systems metaphors into the therapeutic context can also shed light on key aspects of the conduct of therapy that have previously received less attention - such as the emergent and nonlinear aspects of the process (Boston Change Process Study Group, 2005, p. 696). Recognizing the therapy process as an on-going emergent structure with directionality and context-specific internal patterns can heighten the therapist's 'feeling of what happens' (Seligman, 2005; Damasio, 1999) and thus help the therapist to stay heedful of the subtle possibilities of the process for the benefit of the cure. The idea of "directionality" or "purposefulness" as a key feature of the systems concept is particularly significant in the therapy context in as much as the feedback mechanisms and reinforcing loops of the system can be aligned with the therapist's intentions. The alignment to the co-constructed system will involve the reading and sensing of intentions and expectations of the mutually observed other in the "present moment" (Stern, 2004).

Thus more than anything, the systems perspective offers a way to see the therapeutic situation as an emergent field of ongoing, co-created and reciprocal interplay of two self-organizing (sub)systems - that is, subjects - in a process that has high-level unity, shape and direction in spite of being messy, fluid, nonlinear, multidimensional, and context-dependent (Stolorow, 1997, p. 341; Stolorow \& Atwood, 1992, p. 1). This leads to a new understanding of therapeutic change as stemming from perturbations that are powerful enough to disrupt and redirect the patient's current way 


\section{Therapy}

of interpreting the world and shift it into new patterns or attractor states (Beebe et al., 2000, p. 105; Stolorow, 1997, p. 342).

\section{Hidden pitfalls of the systems perspective}

The systems approaches in the therapeutic context in effect propose that there is a holistic structure at play in the therapeutic process over and above the therapist, the patient and the context. A co-constructed and interpersonally regulated dyad between the therapist and the patient (Beebe \& Lachmann, 2005, p. 25) thus becomes an essential unit and a partner to the therapist in the analysis. The therapist's ability to maneuver with this evolving higher-level dynamic entity, conceptualized as a "system", is part of her therapeutic expertise.

But in spite of its proved usefulness in a number of scientific fields, such as biology, ecology, sustainability studies, learning research, business dynamics (see Hammond, 2003), as well as infant research and developmental studies (Thelen \& Smith, 1994), the systems metaphor has been found tricky to implement to the particulars of actual pragmatic contexts. Even in the field of organizational research where the systems concept has been quite extensively discussed for decades (see Jackson, 2000 for an overview), the pragmatic applications of systems thinking have faced significant obstacles. Russell Ackoff (2006), a towering figure in organizational systems thinking, recently felt forced to ask, "why have few organizations adopted systems thinking?" The unfortunate fact is that the scientific study of systems is slow to translate into pragmatic applications. 
The key reason is that as a scientific enterprise systems thinking is primarily a cognitively driven enterprise focused on objective knowledge about systems. This is fine as far as it goes but the fact is that scientific systems thinking primarily yields descriptions of systems as objective entities rather than provide subjectively convincing and pragmatically attractive ways to extend a subject's intrinsic systemic tool set, sensibilities and acumen. Theoretical models are thus the prime focus of systems thinking. As noted by Piers (2005, p. 230) "much of what has been learned in complexity theory has come through the development and use of models, typically mathematical models." The road to a better world is one of increased knowledge and cognitive improvement by people becoming better systems thinkers, i.e., more consciously aware of the relevant systems structures and their dynamic functioning.

Consider the dynamic systems approach of Thelen \& Smith (1994), a standard reference for psychoanalytic theorizers dealing with systems (see for example Coburn, 2002; Stolorow, 1997). Even though Thelen and Smith accurately emphasize that all mental activity is "emergent, situated, historical, and embodied" (Thelen \& Smith, 1994, p. xxiii) they are still viewing mental activity from the impartial, objectifying and scientific perspective. For them the dynamic systems principles offer a "broad, theoretically cogent approach to these problems" (Thelen \& Smith, 1994, p. xxii). Complexity is positioned as a problem that has to be overcome through the development of rigorous scientific principles that model those complexities in a scientifically accurate way. Instead of operating from within the complexity and embracing it as such, their 


\section{Therapy}

"commitment to a biologically consistent theory" (Thelen \& Smith, 1994,

p. xix) means that the effort is to develop a set of exact scientific principles through which the developmental situation can be brought back to the clear daylight of objectifying principles. Though Thelen and Smith acknowledge the "messy" nature of the human behavioral development (Thelen \& Smith, 1994, p. xvi), the crux of their ingenious work is to clear away this messiness using the scientific vocabulary of the dynamic systems theory. In other words, their elaborate theory is an objectifying model to describe the unfolding developmental process. Therefore it is legitimate to ask whether the objective systems language of Thelen \& Smith loses key aspects of the therapeutic situation - those nuanced and lively aspects of it that involve the analyst and the patient as embedded inside the unfolding and emerging dynamic system of the therapeutic encounter in the process of becoming. This is the Achilles' heel of the system metaphor in the therapy context - the "objectivist observing stance" inherent in traditional systems thinking (Stacey, 2003, p. 250) and the cognitivistic and objectivistic overtones of its basic concept. This idealized objectivism hides the fact that the "epistemology of living things" (von Foerster, 1981, p. 257) is always about standing already within the system one is observing through one's limited observing capacities (see also Luoma, Hämäläinen, \& Saarinen, 2010).

Some critiques of relational psychoanalysis have indeed picked on this, accusing the systems therapists of a bias towards the cognitive and conscious. While acknowledging that not all relational analysts fall prey to 
this sin, Mills (2005, p. 160) states that "for many relational analysts, the unconscious has become an antiquated category". In particular, Mills argues that the intersubjective systems theory developed by Stolorow, Atwood and Orange cannot account for the unconscious. Mills states that they replace "psychoanalysis as a science of the unconscious with an intersubjective ontology that gives priority to conscious experience" (Mills, 2005, p. 160). Frank's (1998) examination of Stolorow's (1997) article on 'dynamic, dyadic, intersubjective systems' also accuses Stolorow of the same bias for the cognitive and the conscious. Frank seems to treat relational psychoanalysis as yet another school of psychoanalysis with a fixed set of conscious techniques. Goretti (2001, p. 1215) joins forces by acknowledging Orange et al.'s (1997) critique of technique yet treating their suggestions about therapeutic practice as "rules, and moreover inflexible ones" thus reducing their whole viewpoint into rigid and cognitive rules.

We believe these criticisms are misplaced. However, the critics do have a point if the systems concept is interpreted as an objectival, cognitively accessible category. The systems vocabulary is derived from scientific contexts where the key notions have the tone of precise definitions of mathematical modeling. Indeed, some authors even include discussions about solving nonlinear difference equations as part of their psychoanalytic papers (Piers, 2005, pp. 232-234) . $^{3}$

\footnotetext{
${ }^{3}$ It must be noted that the way Piers (2005) applies these concept to the analysis of the fundamental nature of the self is metaphoric and sensitive to the richness of the therapeutic situation.
} 


\section{Therapy}

Furthermore, there is more to the systems concept in its therapeutic applications than its objectival overtones. Unable to acknowledge this, Mills, Frank and Goretti seem to bypass the emphasis many relational analysts place on non-conscious, non-conceptual, implicit, procedural and intuitive processes. The objectival interpretation is particularly ill-placed in the case of Stolorow and Atwood. Stolorow (1998) goes as far as to say that, the whole point of the Intersubjective Systems Theory is to overcome the traditional conscious and technique-based approach to psychoanalysis. For Stolorow (1997, p. 341) "the very boundary between conscious and unconscious is revealed to be a fluid and ever-shifting one [- -] assembling within a dynamic, dyadic, intersubjective system".

Stolorow, Atwood and Orange abandon the Freudian unconscious as a container of repressed thoughts and feelings, and replace it by prereflective unconsciousness or an experiential horizon, which consists of "an experiential system of expectations, interpretive patterns, and meanings" that are formed through our constant interaction within the intersubjective systems we are part of (Stolorow et al., 2002, p. 45). The same emphasis is also evident in other prominent writers who embrace the system concept in their meta-analysis of the therapeutic situation, for example in the strong emphasis Beebe et al. (2003, p. 744) place upon the implicit and nonverbal dimensions of intersubjectivity ${ }^{4}$ and in the 'implicit relational knowing', which the Boston Group has emphasized as

\footnotetext{
$\overline{{ }^{4} \text { Elsewhere, Beebe et }}$ al. speak of symbolic representational level and perception-action level (Beebe et al., 2000, p. 104).
} 
giving rise to "the foundational level of psychodynamic meaning" (Boston Change Process Study Group, 2007; Lyons-Ruth, 1998; Stern et al., 1998). It is thus clear that Stolorow, Atwood, and Orange, as well as Beebe and Lachmann and the Boston Group, do not assume a cognitively transparent and objectival epistemological relationship between the therapist and a system. However, the possibility of a misinterpretation lurks in the objectivistic overtones of the systems concept itself. Systems thinking by the therapist can easily be interpreted to imply that there is a well-defined something which the therapist can objectify and relate to - the system. As in other forms of systems thinking, the danger is to step outside and adopt a view from without. Indeed, the very usefulness of the systems concept seems to hinge on this possibility. The point of adopting the systems concept is the availability of scientific theories about such systems. As Hämäläinen and Saarinen have emphasized, the systems concept does have a strong ring of something objective, cognitively accessible and from-without-definable. It easily suggests "objectival and even positivistic epistemologies when approaching the humans/systems relationship" (Hämäläinen \& Saarinen, 2008, p. 825). The good news concerning such an objectival and reified interpretation of systems is that one has readily available a huge repertoire of scientific modeling techniques and methodologies. Scientific systems thinking supplies us with an impressive intellectual tool set to understand systems phenomena from without - starting with "dynamic systems models" which Thelen and Smith have brought to the developmental discourse with force and insight. A promise of intellectual clarity and control is readily forthcoming 


\section{Therapy}

along with the rationalistic tool set provided by systems theories. As such a rationalistic concept, the systems construct might lure the therapist into seeking for control of the system and adopting objectivistic tools to manage the therapy system. There is a very real possibility that the therapist may, in some sense, be seduced by the cognitively transparent and rationally attractive methodologies thus dismissing the less-objectival and less-rational, sensibilities-related, non-verbal and implicit aspects of the situation.

These considerations suggest that there is something like an immanent paradox in the systems discourse when applied to the therapy context. On the one hand the systems metaphor seems useful as a notion that leaves behind an isolationist perspective in favor of a more holistic, relational, integrated and emergence-allowing point of view. On the other hand, however, the focus on systems leads to a bird's eye angle that ipso facto abstracts away from the therapist's viewpoint which is necessarily subjective. The therapist is necessarily bound to her own angle and point of view in the course of her therapy. The therapist is not an objective operator but a subjective participant (see especially Buirski, 2007). Any theory of systems objectifies and reifies the concept of a system; it will talk about systems in general, and thus operates with idealizations that bypass the contextually idiosyncratic and epistemically opaque aspects of the therapy situation. However ingenious as a description of the therapy process, an externalist and generic systems description is not of much use to a therapist who is embedded in a living present and in the midst of an 
unfolding therapy session. It is in bridging this gap that we believe the systems inspired therapist could turn to the systems intelligence perspective as an additional viewpoint.

\section{The novel perspective of Systems Intelligence}

Systems intelligence was originally introduced by Raimo P. Hämäläinen and Esa Saarinen as a notion that integrates several distinct discourses and perspectives: the discourses of systems, intelligence and sensibility (Saarinen \& Hämäläinen, 2004, 2010; see also Hämäläinen \& Saarinen, 2006, 2007a, 2008; Luoma et al., 2010, 2008). Working in the context of systems thinking, they approached systems intelligence as "intelligent behaviour in the context of complex systems involving interaction and feedback. A subject acting with Systems Intelligence engages successfully and productively with the holistic feedback mechanisms of her environment. She perceives herself as a part of a whole, the influence of the whole upon herself as well as her own influence upon the whole. By observing her own interdependence in the feedback intensive environment, she is able to act intelligently." (Saarinen \& Hämäläinen, 2004 , p. 3) Or more succinctly: "Systems intelligence involves the ability to use the human sensibilities of systems and reasoning about systems in order to adaptively carry out productive actions within and with respect to systems" (Saarinen \& Hämäläinen, 2010, p. 16).

The points of departure of the systems intelligence perspective included the theory of multiple intelligences (Gardner, 1983), emotional intelligence (Mayer, Salovey, \& Caruso, 2004) and at the same time 


\section{Therapy}

systems thinking, especially the works of Peter Senge (1990; Senge, Kleiner, Roberts, Ross, \& Smith, 1994; Senge et al., 1999) and C. West Churchman $(1968,1979)$. Systems Intelligence refers to the ability, capacity or skill to identify, assess, and manage the systems of one's environment and within one's self. As intelligence, it amounts to a mental ability that permits the recognition, learning, memory for, and capacity to reason (cf. Mayer, Roberts, \& Barsade, 2008); as systems intelligence, it relates specifically to systems. The idea is that humans have a fundamental connectivity to their environment in terms of systems holistic and integrated entities that are evolving, undergo change, initiate and drive change and involve the subject. The chief innovation here is to suggest that a system is a useful metaphor for the "something bigger than self" in the midst of which one's life is evolving, and at the same time to insist that humans have "intelligence" with respect to such entities.

While acknowledging the central role of systems, the Systems Intelligence approach does not endorse the primacy of cognitive understanding or modeling in adapting and dealing successfully with systems. In particular, the relationship of an agent with her environment might well involve what the Boston Group (2005) calls "sloppiness". Moment-to-moment adaptive productivity with the dynamic systems of one's environment and with oneself as a system, might well be based on a multifaceted and multimodal relationship with them and take advantage of a number of channels of relatedness some of which might be non-verbal and implicit. 
In particular, the interface need not reduce to any explicit forms of objectival knowledge. From the point of view of Systems Intelligence, conscious symbolic reflectivity and cognitive rationality provide only some, albeit important, ways of engaging intelligently and successfully with the dynamic systems of one's environment. Without dismissing the merits of the "scientific systems representation methodologies" (Hämäläinen \& Saarinen, 2008, p. 822) ${ }^{5}$, nor the relative value of advancement through making the implicit explicit, the Systems Intelligence perspective sees no reason to restrict the systemic outlook to structures we can objectively represent. "Humans tune to their environment and to other subjects in a number of forms of awareness, mindfulness and connectivity only some of which can be reduced to the traditional cognitive categories of objective knowledge" (Hämäläinen \& Saarinen, 2008, p. 822).

Two ideas are critical for the construct. First, that humans have inherent capabilities to operate intelligently with and within larger-than-themselves wholes and secondly, that it is useful to refer to these wholes as "systems". The idea is to assume that humans have skills and capacities that allow them to identify, assess and live with and within systems. This is intelligence in the customary sense of allowing for adaptability, learning and problem solving (cf. Neisser et al., 1996). It is here assumed that in order to survive the human race must have had some such adaptive and practical endowment to apply in situations arising in complex dynamic

\footnotetext{
${ }^{5}$ Elaborated in great detail by the vast bulk of research on systems thinking (see Ackoff, 1999; Checkland, 1981; Hammond, 2003).
} 


\section{Therapy}

environments and in the living present (Hämäläinen \& Saarinen, 2006, p.

191).

Systems intelligence can be divided into nine broad sets of skills or abilities: (1) systemic perception as situational awareness, comprehension and the ability to perceive various types of life situations as identifiable configurations and as entities with dynamic interconnections; (2) positive attitude as a way of approaching situations, possibilities, contexts and events in a positive way; (3) attunement as the ability to share affects and engage in intersubjectivity (4) self-reflection as the ability to reflect on one's motives, behaviors, ways of thinking and values; (5) perspectivetaking as the ability for reflecting and for adopting new perspectives and interpretations; (6) long-term systemic orientation as an ability to recognize and attend to the cumulative and long-term effects of change particularly in the presence of feedback loops; (7) systems agency with oneself as abilities of mastering oneself as a systemic whole; (8) systems agency with people as abilities of navigating successfully in social situations and of bringing out positive potentials in people; (9) systems agency with general contexts as abilities to adapt and act successfully in different situations, contexts and complex environments.

Systems Intelligence thus highlights the subject's ability to act constructively and productively within emergent wholes as they unfold even when lacking objectival knowledge, codes or techniques (Hämäläinen \& Saarinen, 2007a, p. 5). In addition to what can be cognitively grasped through knowledge and objective forms of 
representation, the Systems Intelligence perspective seeks to account for "an individual's non-rational, non-propositional and non-cognitive capabilities, such as instinctual awareness, touch, 'feel', and sensibilities at large, as capabilities that relate the subject intelligently to a system" (Hämäläinen \& Saarinen, 2006, p. 193). Armed with Systems Intelligence we are able to engage successfully and productively with the holistic feedback mechanisms of the relevant environment (Hämäläinen \& Saarinen, 2006, p. 191). This engagement is not dependent on us taking an external viewpoint of the systems or becoming cognitively aware of their function; "human systems skills, systems sensitivities and pragmatic systems capabilities go far beyond what Systems Thinking seems to have acknowledged" (Hämäläinen \& Saarinen, 2008, p. 821). Instead a person "experiences herself as part of an interdependent environment, aware of the influence of the whole upon herself as well as her own influence upon the whole" (Hämäläinen \& Saarinen, 2006, p. 191). This awareness is likely to be only partially conscious and might involve strong preconscious elements.

Recent infant research provides strong evidence for a fundamental human ability to read social systems preverbally and unconsciously (Beebe \& Lachmann, 2005; Bruner, 1983; Stern, 1985). There is in infants a "readiness to find or invent systematic ways of dealing with social requirements and linguistic forms" (Bruner, 1983, p. 28), a willingness to engage in playful and rhythmic proto-dialogue with a loving parent (Trevarthen, 2008, pp. 16-17) and an "innate capacity for experiencing the complexity of the organism as a whole" (Sander, 1991; Nahum, 2000, 


\section{Therapy}

p. 34). In fact, infant agency as a whole can be thought of as a "systems competence" (Beebe \& Lachmann, 2005, p. 31; Sander, 1985, 1995) and demonstrate what could be called pre-reflective systems intelligence in the infant. Moreover, the unfolding story of the social brain (Brothers, 1997), intention reading and mirror neurons (see also Gallese, 2009; Gallese, Eagle, \& Migone, 2007; for a review, see lacoboni, 2009) and the cognitive and neuroscientific investigation into the social aspects of the human mind (Lieberman, 2007; Hari \& Kujala, 2009) provide support for this precognitive capacity to act intelligently in dynamically complex social and intersubjective systems. As an umbrella term, Systems Intelligence thus encompasses the holistic tradition of systems thinking together with the empirically grounded foundations of early human intersubjectivity and social neuroscience.

Another development that we believe supports the systems intelligence perspective, is the increased focus on the non-conscious processing of information evident in the general psychology (Epstein, 1994, 2002; Kahneman, 2003; Lieberman, 2000; Evans, 2008; Stanovich \& West, 2000). In the "dual-processing accounts" of human reasoning, "system 1" refers to the evolutionarily old processes that are implicit, holistic, rapid, parallel, automatic, heuristic and stimulus bound (Evans, 2008). In contrast to this, "system 2" processes are controlled, rational, systemic, explicit, analytic, slow, and rule based. Previous work on systems thinking has, in effect, focused on system 2 aspects of the human systems endowment. In contrast, the "intelligence" of systems intelligence makes 
use of both of these processing systems, as it is clearly preferable to use the whole of one's repertoire as opposed to only part of it. Thus the originality of the concept lies in its insistence of incorporating system 1 competencies along with system 2 competencies as part of Systems Intelligence.

Parallel evidence is provided by the study of expertise (Ericsson \& Lehmann, 1996; see also Feldon, 2007). Through extended amount of practice experts are able to provide "consistently superior performance on a specific set of representative tasks for a domain" (Ericsson \& Lehmann, 1996, p. 277). It has become evident that the expert's superior performance is not dependent on her cognitive abilities alone but that a large part of the superior performance of experts is linked "to complex representations that are specific to the domain of expertise, and, consequently, were developed as a result of extended exposure and practice" (Ericsson et al., 2009, p. 8). In other words, expertise resides in implicit context-bond heuristics she has acquired through adaptation to the constraints of the environment one operates in (Ericsson \& Lehmann, 1996). This is strikingly demonstrated in a variant of chess called lightning chess where the whole game has to be played in two minutes. In such games most of the moves have to be made in the course of a few seconds or even less - many times as fast as one is able to move one's arms. In spite of the cognitively highly challenging aspects of a chess play, it is evident that in these situations there is no time for any conscious analysis and comparison of alternatives but instead the player must depend entirely on some kind of context-sensitive overall intuition, simply 


\section{Therapy}

responding to the patterns he or she perceives on the board. Surprisingly enough, the Grandmasters are still able to play at almost as high level as their usual play (Dreyfus, 2006, p. 47). Rather than calculating the best move a Grandmaster "experiences a compelling sense of the issue and the best move" (Dreyfus, 2006, p. 47). As a result of what Erickson has called "deliberate practice and the acquisition of complex mechanisms", “chess masters can typically recognize a superior move virtually immediately" (Ericsson, 2006, p. 697). As experts of their specific context they are thus able to respond to the wholeness of the situation. Clearly, some holistic ability is at work, one in which systems skills and abilities (1)-(7) are natural to envision at play.

Likewise, the mastery of an analyst is judged by her performance within real-life therapeutic processes, not by her skilfulness in capturing in some symbolic form what her therapy consists of. Their expertise is demonstrated as much in having cognitive knowledge of the situation as in having a feel for the situation. Sometimes the analyst might act highly idiosyncratically and on the spur of the moment. What sets this response apart from what "anyone might respond in an ordinary social situation" (Hoffman, 2001, p. 181) is the analyst's experience he or she has acquired in the course of her practice and the remarkable fact that even trivial gestures and actions have their meaning in the overall context of that particular therapy. Through continuous exposure to various therapeutic processes with an attitude that Hoffman (2001, p. 181) describes as "a combination of personal openness and a particular kind of perspective on 
the process", the therapist builds up a growing sense of what it means to be subjected to the influence of a whole in the context of the therapy as a particular kind of complex system. In our vocabulary, the therapist engages in a "systems agency with herself" in which her "self reflection and perspective taking" plays an important role and thus she ultimately develops her skills for "systems perception". Importantly, the therapist's experienced expertise enables her to act constructively even in the absence of an explicit justification for the actions and irrespective of what those actions might mean in some other context or as objective phenomena. For example, the pace of speech might be relatively insignificant factor in many communicative contexts but in therapy it can have considerable impact on how the therapeutic situation unfolds (Beebe \& Lachmann, 2005, p. 219). An experienced analyst is indeed likely to use this dimension in her therapy without any conscious choice.

Recent empirical evidence supports the notion that it is the contextual expertise and ability to read subtle cues from the patient rather than restricting oneself to cognitive insights that are behind effective therapy. Using the Analytic Process Scales, Waldron et al. (2004) demonstrated that the impact of analytic activities was strongly dependent on the quality of the interventions and the ability of "saying the right thing at the right time." Waldron et al. (2004, p. 1106) state that "we do not dispute the major importance of interpretation, but [- - ] we did conclude that the other core analytic activities seem equally important, and that none is very effective unless of high quality." Quality here refers to the aptness of the type of intervention, the usefulness of its content and the skill of 


\section{Therapy}

presentation, including tact, timing and language appeal. In their recent summary of their work, the Boston Group (2010) go as far as to state that the "qualitative nature of the whole therapeutic relationship appears to be the most important, specific element in the cure, more than any particular technical activity." The nature of the relationship must be understood in therapy contexts from "the vantage point of the moment-to-moment interaction" (Waldron et al., 2004, p. 1111) where "at every moment, there is the potential to organize expectations of mutuality, intimacy, trust, repair of disruptions, and hope" (Beebe \& Lachmann, 2005, p. 207). We stress that these contextual intricacies implicitly allude to something bigger - the therapeutic process, the unfolding therapy as a whole - that constitutes the higher-level entity in relation to which the acts and choices of the therapist gain their significance. We have chosen to call this higher-level entity system. The systems perspective demonstrates its significance in that a fundamental cornerstone of any systems approach is the emphasis of the whole over and above the parts which are considered to have relevance only in the context of a whole. Becoming sensitive to and skillful with the largely non-verbal subtleties, patterns, demands and possibilities of such systems is part and parcel of the therapist's experienced expertise.

It is important here to recall the enormous complexities and contextual idiosyncrasies that the therapist encounters in her daily work. As noted by Hoffman (2001, p. xii) "technical rationality" pays insufficient attention to the "analyst's personal, subjective involvement, for partially blinding 
emotional entanglement, for the uniqueness of each interaction, for uncertainty and ambiguity, for cultural bias, for change" and "for the analyst's creativity." Following Orange et al. (1997, pp. 68-69) personal experience of the analyst should be seen "as fluid, multidimensional, and exquisitely context-sensitive, with multiple dimensions of experience oscillating between figure and ground, within an ongoing intersubjective system of reciprocal mutual influence." There are thus multiple parallel and mutually interacting processes ongoing within and in-between the patient and the analyst on various different levels - some are explicit and verbal, some implicit and latent, some are affective while others involve attunement to the other and the emerging situation. The processes involve, among others, subtle shifts in physical behavior, gazes, unfulfilled needs, fantasies, self- and interactive regulation, feelings of being influenced, resistance, co-construction, transference and countertransference (Beebe \& Lachmann, 2005). The analyst must have a sense of her own influence on the patient as well as the patient's influence on her, on the influence of the patient's subjective biases on the therapeutic interaction as well as the influence of her own subjective biases. To succeed, the analyst must adopt a way of being with the patient that is responsive and open to all these experiential and intersubjective dimensions. In the midst of this tremendous complexity, the therapist has an additional ally: the therapy process itself envisioned as a system. Like any interesting living system, the therapy system "self-organizes" and exhibits "emergence": exhibits features beyond what the therapist and the patient bring into it as separate individuals. It is with such 


\section{Therapy}

phenomena of self-organization and emergence, facilitated by the therapist, where breakthroughs in treatments will reveal the therapist's true mastery.

An example from Beatrice Beebe is illustrative here. In the course of a late-afternoon session with a patient she calls Burton, "the daylight was beginning to fade. Neither Burton nor I made a move to switch on the light in the room. We entered a slow, near-reverie state, barely talking. We each sensed the other's calming down, and we were both quite content with our silence." (Beebe \& Lachmann, 2005, p. 17.) Beebe notes how this event "marked a shift in our ability to be together in a calmer way" that was "all the more striking in the context of his [Burton's] usually frenetic, urgent, impulsive, wildly emotional state of mind" (Beebe \& Lachmann, 2005, pp. 17-18). Utilizing the setting sun to enhance the therapeutic relationship is something one does not learn from books. Instead, moment of this nature can be seized upon by a positive, systems intelligent, sensitivity-tuned and other-focused therapist open to the emergence of something significant in the context of the co-constructed system as it unfolds. Recall, that in systems, many co-dependent parts can become connected in unexpected ways, resulting in non linear effects as tipping points are reached. A master therapist adapts intelligently to such complex systems in order to benefit the analysand.

Given the stunning intricateness ${ }^{6}$ of the therapy process, it is clear that no tool set will be sufficient and that technicalities will always have to be

\footnotetext{
${ }^{6}$ In the systems language we could speak of the plurality of different dynamic systems operating in the analytic situation.
} 
augmented through human sensibilities and with nuanced brilliance in often unique interventions as brought to bear on the overall setup. The human "habit of fragmentary thought" which "divides everything up" (Bohm, 1996, p. 9) that is embraced by the scientific method has to give way for a more holistic, feel-based engagement with the therapeutic system. Indeed, following the relational turn, the whole idea of analytic "techniques" is open to be viewed with some suspicion; any use of technique should be understood as highly dependent on the personality, training and clinical experience of the individual analyst and the dyadic context in which it is applied (see Seligman, 2007). The human capacity for conscious processing is critical, just as in chess where "serious chess players spend as much as four hours a day engaged in this type of solitary study [careful and extended analysis]" (Ericsson, 2006, p. 697).

Demonstrably, when it comes to some key aspects of the mastery of therapy, just as in most other forms of expertise, endless hours of practice are pivotal.

The insight of Systems Intelligence is that we already possess much more intelligence than we ordinarily acknowledge. As human beings we are tuned to act intelligently with larger-than-ourselves wholes in spite of our cognitive limitations on knowing those wholes objectively and in spite of our often-severe limitations in describing them. This intelligence of action amounts to adaptability, learning and productivity within complex dynamic environments, with respect to social situations and holistic contexts in which our life unfolds; it amounts to the ability to use the human sensibilities and reasoning in order to "adaptively carry out 


\section{Therapy}

productive actions within and with respect to systems" (Saarinen \& Hämäläinen, 2010, p. 16). Much of that intelligence goes beyond the explicit or the conscious. This means that an overemphasis of the rational and explicit intelligence, as opposed to systems intelligence, can lead to pitfalls. A powerful demonstration of this phenomenon in the therapy context is provided by Heller and Haynal (1997; as reported by Beebe et al., 2003, p. 749). They videotaped the faces of the doctor and the patient in fifty-nine psychiatric encounters where patients who had recently attempted suicide were interviewed by the same psychiatrist. A year later ten of these patients had made another suicide attempt. The psychiatrist's own written reports could not predict reattempters but "finegrained microanalyses of the videotapes of the psychiatrist's face identified $81 \%$ of the reattempters. When dealing with her patients who would later make another suicide attempt, the psychiatrist frowned more, showed more head and eye orientation, and showed more overall facial activation and increased speech" (Beebe et al., 2003, p. 749). The psychiatrist was able to detect the potential reattempters on an implicit level and even able to behave differently with them without any awareness of this difference on a conscious level. In other words, on the level of sensing the patient's situation, the doctor got it more right than on the level of her rational account of it.

As Beebe et al. stress any model of therapeutic action must include the two levels of connecting with the other: "Essentially, psychoanalysis needs a theory of interaction that integrates both verbal and nonverbal, 
explicit and implicit communication." (Beebe et al., 2000, p. 116; see also Pally, 1998). The systems intelligence perspective provides the foundations for such a theory. It can help us understand how our inner systems are moulded by constant exposure to the therapeutic context and how such moulding gradually leads to an expertise within therapeutic situations, both on cognitive and on pre-cognitive level. Our proposition is thus that as systems perspective is adopted as part of the therapeutic understanding, careful measures should be taken in order not to associate the perspective with mainstream systems thinking with its implicit bias for the objective, cognitive and rational.

\section{Therapy with systems intelligence}

Within the systems framework the Systems Intelligence perspective is radical because it does not prioritize any objectival, rational or explicit discourse or ways of modeling. Instead of models, it emphasizes the bringing forth of beneficial outcomes. In Systems Intelligence "a system that works comes first; understanding and explaining why it works comes second" (Hämäläinen \& Saarinen, 2006, p. 193). In that sense, the systems intelligence perspective acknowledges the tacit and inarticulate, attunement-related aspects of an analyst's practical acumen along with the more customary articulate and objectively identified tools. A systems intelligent analyst is thus aiming towards "optimal therapeutic interaction" and responsiveness (Bacal \& Herzog, 2003, p. 636) in which one is monitoring patient's cues on both conscious and preconscious levels to be able to choose one's responses based on their "ultimate therapeutic 


\section{Therapy}

potential" (Bacal \& Herzog, 2003, p. 642). That potential will involve finegrained elements that might seem to be mundane and barely noticeable per se but may gain momentum through the amplifying force of the (therapeutic) system. An experienced analyst is armed with a keen sensibility of what kind of behavior might be appropriate in a given situation. Her expertise will involve procedural knowledge (Fosshage, 2005), interpersonal sensitivity (Hall \& Bernieri, 2001) and intersubjective systems sensibility (Buirski 2007: xv). These abilities build up her intelligence towards the therapeutic situation as a holistic entity in the process of becoming and with features beyond her knowing - her systems intelligence.

Systems intelligence thus provides an umbrella term to help to explain the analyst's ability to act intelligently in a mutually created intersubjective therapeutic system as it unfolds. We feel confident in claiming that the Systems Intelligence perspective provides a crucial missing link between the de facto practices of a successful analyst and the systems perspectives that have been provided by systems inspired theoreticians of psychotherapy.

Let us call an analyst systems intelligent to the extent she engages successfully and productively within the dynamic therapeutic system as it emerges even in the absence of knowledge and objectival representations of that system. She is aware of the influence of the whole upon herself and her own influence upon the whole and is sensitive to the emergent potentials that can unfold within and through that whole. Notice that this 
will involve attunement not only to the patient but also with respect to the system as a whole - the therapy as a process. The system as a "third party" (Jones \& Corner, 2007, p. 240) will serve the therapist as an ally. Sensing the direction of the system as an all encompassing dynamic complex, the therapist makes use of its hidden possibilities. Steven Stern (2009, p. 152) provides an apt example of how to tune to the therapeutic system as a whole sensing intuitively one's way towards the emerging possibilities. Growing irritated by a patient who regularly missed sessions he decided to state out loud this dislike to the patient. The patient was stunned by his outspokenness but later this turned out to be "extremely important" and a turning point in their therapeutic relationship (Stern, 2009, p. 156). Stern reflects: "I think of our subjectivities as having become intertwined in a particular way, and that when I said what I did it registered with Linda as both emerging from and addressing something she had played a part in" (Stern, 2009, p. 156). Thus his actions were addressing a systems level of the therapeutic encounter that he felt that they were both in contact with. Notice how Stern's action involved the dimensions of "systemic perception", "attunement", as well as "systems agency with people", and how his reflection about it involved a keen ability for "self-reflection". In the therapy process - conceived as a vaguely defined yet from-within identifiable dynamical complex whole the therapist is aware that sometimes she may be in a position to apply specific models, representations or techniques in order to act intelligently and sometimes not. She is attuned to the subtle and specific aspects of the multidimensional system she is involved with. Her focus is on getting 


\section{Therapy}

it right with whatever the system is, as opposed to being able to describe how to get it right. The therapist's sensibilities and attunement with the system and with the patient will thus provide a channel for the therapy to succeed. Transactional thinking and transactional competence is systems intelligence in the therapy context (cf. Seligman, 2005, p. 288).

The unit that ultimately delivers the cure is the entire co-created system with all its vagaries and subtle complexities and internal logic. Individual moves, gestures, ebbs and flows, alignings and realignings, speech acts and interpretations on the part of the analyst, however appropriate and ingenious, will gain their significance only via the overall structure the therapist co-creates moment-by-moment with her patient. The "fitness" and "directionality" that the Boston Group emphasize as fundamental to the success of the process, are dependent on the whole and reflect the system which in turn arises as a result of the "continuous, reciprocally influenced process, constructed moment to moment by both partners", as Beebe \& Lachmann (2005, p. 207) put it. It is critical to the systems intelligence perspective that the therapist draws from elements that reflect the whole even though the whole is in the process of becoming and cannot be related to explicitly or in objectival terms. We believe this is in line with the actual therapeutic practice. The "systems" that leading systems inspired therapists like Sander, Stolorow \& Atwood, Beebe \& Lachmann, the Boston Group, Seligman and Galatzer-Levy have been talking about are systems of systems intelligence, as opposed to systems in the sense of scientific systems thinking or systems dynamics. As we 
interpret them, leading systems therapists highlight the systems intelligence of the therapist instead of her systems thinking and modeling skills. So when Seligman writes that "transactional thinking is a key aspect of systems thinking" (Seligman, 2005, p. 288) what he really means is the therapist's systems intelligence.

Inside the psychoanalytic tradition, Wilma Bucci (1997, p. 158) captures well the dimension of the implicit that is critical for systems intelligence, when she states that "the analyst perceives and responds to his patient on multiple, continuous dimensions, including some that are not explicitly identified. The analyst is able to make fine distinctions between a patient's states [- -] without being able to express those feelings in words." In other words, the analyst has an ability of sensing and experiencing the subtleties of the system as well as its systemic possibilities which might involve emergence and points of non linear progress. Based on her affective sensibilities and nonverbal instincts and guided by her cognitive understanding, her actions are often facilitated intelligently by the system whilst also facilitating the system intelligently. The unfolding therapeutic process can thus move into the right direction without the analyst knowing the rationale for her actions - much of the time something just feels right and things just seem to fall into place. As O'Hanlan and Wilk (1987, p. ix) put it: "Sooner or later in the professional life of every agent of change, in every field of human endeavor, there comes an experience of achieving results beyond what theory would have led one to believe was possible." In other words, through practice, the analyst develops an enriched experience of the dynamics of the therapy 


\section{Therapy}

process and cultivates her "intersubjective systems sensibility" (Buirski, 2007, p. xv). This explains Symington's (1983, p. 286) discovery that "when I acted from personal freedom rather than follow some specific technical regulation that is supposed to be followed in an analysis then therapeutic shifts occurred." Instead of analyzing her continuing unconscious and affect-laden influences on and attunement with the therapeutic system, the analyst primarily utilizes them. This is her Systems Intelligence at work.

We place emphasis on the observation that Systems Intelligence becomes increasingly instinctive as a therapist grows through experience. She keeps track of the whole, she looks at the long term effects. The "therapist continually wonders how he is being experienced by the patient, monitoring the patient's reactions to his responses so as to ascertain the mutative or traumatic potential of their interactions" (Bacal $\&$ Herzog, 2003, p. 644). She combines systemic reflection with systemic perception, perspective taking and systemic action with the patient while staying systemic with herself. A particularly good example of systemic action in therapy might be the utilization of humor (on the general functions of humor, see Gervais \& Wilson, 2005). To be able to use humor successfully in a therapy one has to be particularly sensitive with respect to the whole of the therapy. Humor often operates on the thin line between what is appropriate and what is not. But the potential benefits are considerable. As Stern testifies: "I find that with certain patients humor and playfulness can work powerfully to counteract long-standing, 
debilitating organizing principles. Usually humor of this kind arises spontaneously and unbidden- especially the first time it comes into play. A joke comes to mind that reframes a deadly serious area of psychic quicksand so that suddenly there is an intersubjective rope to grab a hold of and the deadly serious issue can be mentalized in a new way. A new kind of fittedness has been achieved." (Stern, 2009, pp. 148-149.) Humor thus operates on the platform of systemicity and carries the promise of emergence. It is through the therapy system as a whole and with respect to the demands of the moment that the validity of the humorous act will be decided.

The point we are making here is reinforced by Seligman when he notes how "analysts make decisions all the time on the basis of their implicit recognition that the effect of a single factor or intervention depends on the overall situation" (Seligman, 2005, p. 289). Our systems intelligence perspective aims to conceptualize some of the features of this mastery. Our initiative pushes further the key thesis of Seligman (2005, p. 297) when he states that "system theories explicate what good therapists already do." At the same time, our proposal welcomes the cultivated, multidisciplinary, pluralistic and broadly tuned study of the human endowment in its full multisensory capabilities for the purposes of therapy. Indeed, our point is that the rationalistic modeling of the therapy situation inadvertently trivialize some aspects of the human sensibility and good therapeutic practices on the grounds that they do not fit in with a given theoretic framework. At worst it amounts to understanding the classical theories of psychoanalysis as propagating the idea that "the 


\section{Therapy}

analyst abstain from any personally expressive behavior", as Hoffman (2001, p. 2) describes it. As has been pointed out in the literature, the intellectualist conception of rationality found in many psychoanalytic writings may amount to a "discontinuity of knowledge and action" (Fourcher, 1996, p. 524). The implicit assumption of such overzealous rationalism is that the analyst should be able to rationally justify the techniques and interventions she performs in her actual practice ${ }^{7}$. This has been taken furthest in the increased calls for evidence-based treatment (see e.g. Fonagy \& Roth, 1996; Kazdin, 2008; Margison et al., 2000 ) that put pressure on the analyst to restrict the range of analytic interventions to those that have been proved effective through empirical findings. Such a call for objectivism, however tempting on the basis of accountability, can easily lead analysts to avoid the more instinctual, sensibility-intensive and 'irrational' forms of action which emerge from her own humanity and are also critical for her relational mastery as a cocreational partner in the dyadic system of the therapy process.

Systems Intelligence does not dismiss the necessity of developing rationally justified techniques: “Nothing in what we suggest takes away the necessity to analyze, to conceptualize in objective terms, to measure, to know and to engineer, to command and control - to the extent we can

\footnotetext{
${ }_{7}$ Buirski's (2007: 19-38) reinterpretation of a previously documented analysis provides a good illustration of the problems that come up when the analyst doesn't seem to show systems intelligence or intersubjective systems sensitivity. The analyst seems to be ignorant of the unique nature of the patient at hand, their relationship and his own influence on the patient. Instead he is imposing his own theory-driven interpretations without sensitivity to the reality experienced by the patient.
} 
do it, and to the extent it is beneficial in a given context to do it" (Hämäläinen \& Saarinen, 2007a, p. 30). Systems Intelligence as part of a moment-to-moment human aliveness "will connect with analytic and propositional knowledge where such is available" (Hämäläinen \& Saarinen, 2007b, p. 297). Empirical methods of evaluation can assist good therapy when used in proper ways and when one is well aware of their limits (see Kazdin, 2008). The relational turn in psychoanalysis has highlighted the embedded and affect-laden nature of the therapeutic encounter. Taking this as a starting-point, it is easy to see how any implicitly objectifying and rationality-driven approach will significantly reduce the impact of the therapy in certain cases. Cognitive comprehensibility of the therapeutic process is not the ultimate goal of a therapy; enhancing the patient's life is. Expertise is not restricted to "detached rule-following" but stems from a "more involved and situationspecific" way of acting in the situation (Dreyfus, 2006, p. 26). When rationally available techniques have all been deployed there is still a huge field open for interventions that are based on the systemic expertise of the analyst in her context-specific and implicit, procedural and instinctual mastery of 'dancing with systems' (to borrow a phrase from Meadows, 2002).

On the basis of these considerations it is clear that the systems intelligent analyst will be encouraged to use her intuitions and other "system 1" related skills when engaging with her patient in the co-creational dyad. Her sensitivities are a major asset she possesses when immersing herself in the praxis of her profession. Systems Intelligence highlights the vast, 


\section{Therapy}

implicit practical knowledge and ways of interrelating which are available to the analyst in her work. Understanding this, the analyst will be encouraged to finetune her instincts and sensibilities to connect with the various explicit and implicit elements of the situation including its potentially emergent features. She is likely to be more daring with what she holistically feels to be the right action - regarding as secondary the question of theoretical justification.

Additionally, the relation of implicit and explicit should not be seen as mutually exclusive. In the best case scenario the implicit and explicit are both present simultaneously as a "reflection-in-action" (Schön, 1983) where "the analyst's action is immediately experienced by the analyst as both a genuine expression of some aspect of his or her personal experience and as theoretically informed" (Hoffman, 2001, p. 182). In these situations the mutative force of the analysis is built up through a dialectic between two elements: firstly, through the analyst's authority based on "adherence to psychoanalytic rituals", and secondly through behavior "that is sufficiently self-expressive and spontaneous so that a bond of mutual identification can develop between the participants" (Hoffman, 2001, p. xxvii).

An illustrative example of a Systems Intelligent analyst in action is provided by Herbert Rabin (1995, p. 472). He describes how her patient Jean, a 35-year-old 'tough' professional woman - broke down in tears in the midst of the session communicating excruciating pain and in an emotionally loaded moment stretched her hand over the couch. He 
spontaneously grasped her hand and held it for a moment. They were both moved. Years later Rabin described this as a "powerful curative moment in Jean's analysis". But because of his Freudian psychoanalytic training that emphasized abstinence "I was not able to discuss these important transactional events with my analytic supervisor because I felt ashamed. I had fallen from my own analytic ideal, because I had gratified the patient." (Rabin, 1995, p. 472.) In the moment when the woman stretched her hand over two powerful currents of thought activated inside Rabin. His conscious, analytically trained and cognitive self preached abstinence: he should not react to the pleading hand as this would commit the sin of gratifying the patient. At the same time, however, his humane systems intelligent instincts suggested the seemingly improper alternative. The decision Rabin made was not a comment concerning the grasping of a patient's hand as a separate, generalizable behavior but an evaluation of a larger whole in the process of becoming and as influenced by that act when conducted in a particular way. The genius of the therapist amounted to an instantaneous holistic attunement with a unique possibility as it presented itself in the context of that particular therapy process conceived as a whole. Within the indeterminate, and stupendously complex whole of the therapy process, the therapist felt that this particular act would have a positive impact this particular time, as indeed it did. The act was not just a gesture of human significance from the therapist to a fellow human being in a desperate need of comfort. His grasping her hand amounted to an instinctual micro-behavioral systems intervention that worked because the system supported the act. 


\section{Therapy}

\section{Conclusion}

The relational movement has made important steps in enhancing the meta-understanding of the therapeutic situation. As part of the relational turn, the therapists inspired by the systems metaphor have provided further understanding in demonstrating the intricacy with which the analyst and patient are interconnected. The recognition of the analytic situation "as a dyadic intersubjective system of reciprocal mutual influence, to which the organizing activities of both participants make ongoing, codetermining contributions" (Orange et al., 1997, p. 43) is indeed ground-breaking. This has enabled analysts to more fruitfully approach the affect-laden and context-bound features of the therapeutic situation, along with its call for reciprocity, complexity, intersubjectivity, sensitivity and possibilities for non-linear change. It has illuminated the therapeutic situation as a mutually created and unfolding dynamic system that opens up and closes certain possibilities much of which operates outside of the cognitive-rational awareness. As part of the "larger theoretical 'movement towards freedom' within psychoanalysis" (Stern, 2009 , p. 145) the relational and systemic perspective has provided a meta-theoretical justification for the sensibilities that enable the analyst to take into account and emphasize the subtle and contextual but crucially important aspects of the therapeutic situation. This has resulted in a “marked liberating impact upon psychoanalytic practice” (Rabin, 1995, p. 467): a less rule-oriented, less adversial and more empathic therapeutic perspective. The analyst is more open to "acts of freedom" (Symington, 
1983) and "spontaneous and unpremeditated gestures" (Seligman, 2005, p. 307), is more willing to engage in improvisational relating in which the therapist "exercises his or her latitude for spontaneous, true-self expression without immediate reflection" (Coburn, 2002, p. 664; see also Ringstrom, 2001) and is open to "spontaneous emergence of new discoveries" that happen 'in the moment' when the analyst and the patient "are fully engaged with each other" (Fogel, King, \& Shanker, 2008, p. 249). The systems intelligence perspective presented here reinforces these conclusions by emphasizing the therapist's holistic sensibilities that connect with the therapy as a whole, as a unique intersubjective and cocreational unfolding with often hard-to-explain and associative projections to the future as part of its constitution.

Highlighting the therapist's "system 1" -acumen and subtleties of actual conduct, the systems intelligence perspective on therapy emphasizes the human sensibilities and feel-like dimensions of the therapist's professionalism while preserving the therapy process as an integrated entity with the key concept of a system. It encourages analysts to proceed with prudence beyond what they can justify on rational grounds and to stay on course even when lacking a cognitive grasp of the situation and in the absence of a technique. Indeed, the systems intelligence perspective emphasizes the importance of trying to address what experienced therapists are likely to have sensed as fundamental all along: the necessity to cultivate one's context-tuned sensibilities and competences to preconsciously sense the particulars of the situation at hand in order to feel the right way forward with the given patient within the particular 


\section{Therapy}

therapeutic situation in the larger whole that the therapy constitutes as a system.

Systems intelligence thus strengthens the relational movement by supplying a redefined conceptualization of a system - one that does better justice to the actual practice of the analyst as well as to the intuitions and articulations of many of the key writers using the systems metaphor to conceptualize the therapeutic encounter. The systems intelligent view of the therapy context does not take an objectival, outsiders perspective towards it but instead recognizes the role of the analyst as embedded inside a dynamic system within which she is able to sense her way forward. The chief thesis of this paper is that this is the natural mindset of the analysts in their daily work. In so far as that mindset largely remains unexpressed, it seems to us that a vast potential source for therapeutic advancement remains untapped. With the awareness that this is an incredibly hard-to-define phenomenon the present paper makes an attempt to clarify the naturalistic foundations of systemically attuned good therapeutic practice thus taking a step forward in comprehending and utilizing it more fully.

\section{REFERENCES}

Ackoff, R. L. (1999). Re-creating the corporation: A design of organizations for the 21st century. Oxford University Press, USA.

Ackoff, R. L. (2006). Why few organizations adopt systems thinking. Systems Research and Behavioral Science, 23(5), 705-708.

Bacal, H. A., \& Herzog, B. (2003). Specificity theory and optimal responsiveness: An outline. Psychoanalytic Psychology, 20(4), 635-648.

Beebe, B., Jaffe, J., Lachmann, F., Feldstein, S., Crown, C., \& Jasnow, M. (2000). Systems models in development and psychoanalysis: The case of vocal rhythm coordination and attachment. Infant Mental Health Journal, 21(12), 99-122.

Beebe, B., Knoblauch, S., Rustin, J., \& Sorter, D. (2003). Introduction: A systems view. Psychoanalytic Dialogues, 
13(6), 743-775.

Beebe, B., \& Lachmann, F. (2003). The relational turn in psychoanalysis: A dyadic systems view from infant research. Contemporary Psychoanalysis, 39(3), 379-409.

Beebe, B., \& Lachmann, F. (2005). Infant research and adult treatment: Co-constructing interactions. New York: The Analytic Press.

Bertalanffy, L. V. (1968). General systems theory. New York: Braziller.

Bohm, D. (1996). On dialogue. New York: Routledge.

Boston Change Process Study Group. (2002). Explicating the implicit: The local level and the microprocess of change in the analytic situation. International Journal of Psycho-Analysis, 83(5), 1051-1062.

Boston Change Process Study Group. (2005). The "something more” than interpretation revisited: sloppiness and co-creativity in the psychoanalytic encounter. Journal of the American Psychoanalytic Association, 53(3), 693729.

Boston Change Process Study Group. (2007). The foundational level of psychodynamic meaning: Implicit process in relation to conflict, defense and the dynamic uncounscious. International Journal of Psychoanalysis, 88, 843860.

Boston Change Process Study Group. (2010). Change in psychotherapy: A unifying paradigm. New York: Norton.

Brothers, L. (1997). Friday's footprint: How society shapes the human mind. New York: Oxford University Press.

Bruner, J. (1983). Child's talk: Learning to use language. New York: W. W. Norton.

Bucci, W. (1997). Patterns of discourse in" good" and troubled hours: A multiple code interpretation. Journal of the American Psychoanalytic Association, 45(1), 155-187.

Buirski, P. (2007). Practicing intersubjectively. Plymouth: Jason Aronson.

Checkland, P. B. (1981). Systems thinking, systems practice. Chichester: Wiley.

Churchman, C. W. (1968). Challenge to reason. New York: McGraw-Hill Inc.

Churchman, C. W. (1979). The systems approach and its enemies. New York: Basic Books.

Coburn, W. J. (2002). A world of systems: The role of systemic patterns of experience in the therapeutic process. Psychoanalytic Inquiry, 22(5), 655-677.

Damasio, A. R. (1999). The feeling of what happens: Body and emotion in the making of consciousness. New York: Harcourt.

Dreyfus, H. L. (2006). Overcoming the myth of the mental. Topoi, 25(1), 43-49.

Dunn, J. (1995). Intersubjectivity in psychoanalysis: A critical review. International Journal of Psycho-Analysis, 76, 723-738.

Epstein, S. (1994). Integration of the cognitive and the psychodynamic unconscious. American Psychologist, 49, 709-724.

Epstein, S. (2002). Cognitive-experiential self-theory of personality. In T. Millon \& M. J. Lerner (Eds.), Comprehensive handbook of psychology. Volume 5: Personality and social psychology (pp. 159-184). Hoboken, NJ: Wiley.

Ericsson, K. A. (2006). The influence of experience and deliberate practice on the development of superior expert performance. In K. A. Ericsson, N. Charness, P. J. Feltovich, \& R. R. Hoffman (Eds.), The Cambridge handbook of expertise and expert performance (pp. 683-703). Cambridge, UK.: Cambridge University Press.

Ericsson, K. A., \& Lehmann, A. C. (1996). Expert and exceptional performance: Evidence of maximal adaptation to task constraints. Annual review of psychology, 47(1), 273-305.

Ericsson, K. A., Perez, R. S., Eccles, D. W., Langh, L., Baker, E. L., Bransford, J. D., Vanlehn, K., et al. (2009). The measurement and development of professional performance: An introduction to the topic and a background to the design and origin of this book. In K. A. Ericsson (Ed.), Development of professional expertise: Toward measurement of expert performance and design of optimal learning environments (pp. 1-25). New York: Cambridge University Press.

Evans, J. S. B. (2008). Dual-processing accounts of reasoning, judgment, and social cognition. Annual Review of Psychology, 59, 255-278.

Feldon, D. F. (2007). The implications of research on expertise for curriculum and pedagogy. Educational Psychology Review, 19(2), 91-110.

von Foerster, H. (1981). Observing systems. Seaside, Ca.: Intersystems Publications.

Fogel, A., King, B. J., \& Shanker, S. G. (2008). Human development in the twenty-first century: Visionary ideas from systems scientists. Cambridge: Cambridge University Press. 


\section{Therapy}

Fonagy, P., \& Roth, A. (1996). What works for whom? A critical review of psychotherapy research. New York: Guilford Press.

Fosshage, J. L. (2005). The explicit and implicit domains in psychoanalytic change. Psychoanalytic Inquiry, 25(4), 516-539.

Fourcher, L. A. (1996). The authority of logic and the logic of authority: The import of the Grünbaum debate for psychoanalytically informed psychotherapy. Psychoanalytic Dialogues, 6(4), 515-532.

Frank, G. (1998). The intersubjective school of psychoanalysis: Concerns and questions. Psychoanalytic Psychology, 15(3), 420-423.

Galatzer-Levy, R. M. (2004). Chaotic possibilities: Toward a new model of development. International Journal of Psycho-analysis, 85(2), 419-441.

Galatzer-Levy, R. M. (2009a). Finding your way through chaos, fractals, and other exotic mathematical objects: A guide for the perplexed. Journal of the American Psychoanalytic Association, 57(5), 1227-1249.

Galatzer-Levy, R. M. (2009b). Good vibrations: Analytic process as coupled oscillations. The International Journal of Psychoanalysis, 90(5), 983-1007.

Gallese, V. (2009). Mirror neurons, embodied simulation, and the neural basis of social identification. Psychoanalytic Dialogues, 19(5), 519-536.

Gallese, V., Eagle, M. N., \& Migone, P. (2007). Intentional attunement: Mirror neurons and the neural underpinnings of interpersonal relations. Journal of the American Psychoanalytic Association, 55(1), 131-176.

Gardner, H. (1983). Frames of mind. Basic Books New York.

Gervais, M., \& Wilson, D. S. (2005). The evolution and functions of laughter and humor: A synthetic approach. The Quarterly Review of Biology, 80(4), 395-430.

Goldberg, A. (2001). Postmodern psychoanalysis. International Journal of Psycho-Analysis, 82(1), 123-128.

Goretti, G. R. (2001). The myth and history of some psychoanalytic concepts: Thoughts inspired by a reading of Orange et al., Working intersubjectively. International Journal of Psycho-Analysis, 82(6), 1205-1223.

Hall, J. A., \& Bernieri, F. J. (Eds.). (2001). Interpersonal sensitivity: Theory and measurement. Mahwah, NJ.: Lawrence Erlbaum.

Hammond, D. (2003). The science of synthesis: Exploring the social implications of general systems theory. Boulder, Colorado: University Press of Colorado.

Hari, R., \& Kujala, M. V. (2009). Brain basis of human social interaction: From concepts to brain imaging. Physiological reviews, 89(2), 453-479.

Harris, A. (2009). Gender as soft assembly. New York: Routledge.

Heller, M., \& Haynal, V. (1997). The doctor's face: A mirror of his patient's suicidal projects. In J. Guimon (Ed.), The Body in Psychotherapy (pp. 46-51). Basel: S. Karger.

Hoffman, I. Z. (2001). Ritual and spontaneity in the psychoanalytic process - A dialectical-constructivist view. Hillsdale, NJ.: Analytic Press.

Hämäläinen, R. P., \& Saarinen, E. (2006). Systems intelligence: A key competence in human action and organizational life. The SoL Journal, 7(4), 17-28.

Hämäläinen, R. P., \& Saarinen, E. (2007a). Systems intelligent leadership. In R. P. Hämäläinen \& E. Saarinen (Eds.), Systems Intelligence in Leadership and Everyday Life (pp. 3-38). Espoo: Helsinki University of Technology, Systems Analysis Laboratory.

Hämäläinen, R. P., \& Saarinen, E. (2007b). The way forward with systems intelligence. In R. P. Hämäläinen \& E. Saarinen (Eds.), Systems Intelligence in Leadership and Everyday Life (pp. 295-305). Espoo: Helsinki University of Technology, Systems Analysis Laboratory.

Hämäläinen, R. P., \& Saarinen, E. (2008). Systems intelligence - the way forward? A note on Ackoff's' why few organizations adopt systems thinking'. Systems Research and Behavioral Science, 25(6), 821-825.

Iacoboni, M. (2009). Imitation, empathy, and mirror neurons. Annual Review of Psychology, 60, 653-670.

Jackson, M. C. (2000). Systems approaches to management. New York: Kluwer Academic / Plenum Publishers.

Jackson, M. C. (2003). Systems thinking: Creative holism for managers. Chichester: Wiley.

Jones, R., \& Corner, J. (2007). Systems intelligence and its relationship to communication theories. In R. P. Hämäläinen \& E. Saarinen (Eds.), Systems Intelligence in Leadership and Everyday Life (pp. 240-249). Espoo: Helsinki University of Technology, Systems Analysis Laboratory.

Kahneman, D. (2003). A perspective on judgment and choice: Mapping bounded rationality. American 
Psychologist, 58(9), 697-720.

Kazdin, A. E. (2008). Evidence-based treatment and practice: New opportunities to bridge clinical research and practice, enhance the knowledge base, and improve patient care. American Psychologist, 63(3), 146-159.

Lieberman, M. D. (2000). Intuition: A social cognitive neuroscience approach. Psychological Bulletin, 126(1), 109137.

Lieberman, M. D. (2007). Social cognitive neuroscience: a review of core processes. Annual Review of Psychology, 58, 259-289.

Luoma, J., Hämäläinen, R. P., \& Saarinen, E. (2008). Perspectives on team dynamics: Meta learning and systems intelligence. Systems Research and Behavioral Science, 25(6), 757-767.

Luoma, J., Hämäläinen, R. P., \& Saarinen, E. (2010). Acting with systems intelligence: Integrating complex responsive processes with the systems perspective. Journal of Operational Research Society, Forthcoming.

Lyons-Ruth, K. (1998). Implicit relational knowing: Its role in development and psychoanalytic treatment. Infant Mental Health Journal, 19(3), 282-289.

Margison, F. R., Barkham, M., Evans, C., McGrath, G., Clark, J. M., Audin, K., \& Connell, J. (2000). Measurement and psychotherapy: Evidence-based practice and practice-based evidence. The British Journal of Psychiatry, 177(2), 123-130.

Marzi, A., Hautmann, G., \& Maestro, S. (2006). Critical reflections on intersubjectivity in psychoanalysis. International Journal of Psycho-Analysis, 87(5), 1297-1314.

Mayer, J. D., Roberts, R., \& Barsade, S. (2008). Human abilities: Emotional intelligence. Annual Review of Psychology, 59, 507-536.

Mayer, J. D., Salovey, P., \& Caruso, D. R. (2004). Emotional intelligence: Theory, findings, and implications. Psychological Inquiry, 15(3), 197-215.

Meadows, D. H. (2002). Dancing with systems. Systems Thinker, 13(2), 2-6.

Mills, J. (2005). A critique of relational psychoanalysis. Psychoanalytic Psychology, 22(2), 155-188.

Mitchell, S. A. (1988). Relational concepts in psychoanalysis: An integration. Cambridge, Mass.: Harvard University Press.

Nahum, J. P. (2000). An overview of Louis Sander's contribution to the field of mental health. Infant Mental Health Journal, 21(1-2), 29-41.

Neisser, U., Boodoo, G., Bouchard, T. J., Boykin, A. W., Brody, N., Ceci, S. J., Halpern, D. F., et al. (1996). Intelligence: Knowns and unknowns. American psychologist, 51(2), 77-101.

O'Hanlon, B., \& Wilk, J. (1987). Shifting contexts: The generation of effective psychotherapy. New York: Guilford Press.

Orange, D. M., Atwood, G. E., \& Stolorow, R. D. (1997). Working intersubjectively: Contextualism in psychoanalytic practice. Hillsdale, NJ.: Analytic Press.

Pally, R. (1998). Emotional processing: The mind-body connection. International Journal of Psycho-Analysis, 79, 349-362.

Piers, C. (2005). The mind's multiplicity and continuity. Psychoanalytic Dialogues, 15(2), 229-254.

Rabin, H. M. (1995). The liberating effect on the analyst of the paradigm shift in psychoanalysis. Psychoanalytic Psychology, 12(4), 467-481.

Ramage, M., \& Shipp, K. (2009). Systems thinkers. London: Springer.

Ringstrom, P. A. (2001). Cultivating the improvisational in psychoanalytic treatment. Psychoanalytic Dialogues, 11(5), 727-754.

Saarinen, E., \& Hämäläinen, R. P. (2004). Systems intelligence: Connecting engineering thinking with human sensitivity. In R. P. Hämäläinen \& E. Saarinen (Eds.), Systems Intelligence - Discovering a Hidden Competence in Human Action and Organizational Life (pp. 9-37). Espoo: Helsinki University of Technology, Systems Analysis Laboratory Research Reports, A88.

Saarinen, E., \& Hämäläinen, R. P. (2010). The originality of systems intelligence. In R. P. Hämäläinen \& E. Saarinen (Eds.), Essays on Systems Intelligence (pp. 9-28). Espoo: Aalto University, Systems Analysis Laboratory.

Sander, L. W. (1977). The regulation of exchange in the infant-caretaker system and some aspects of the contextcontent relationship. In M. Lewis \& L. Rosenblum (Eds.), Interaction, conversation, and the development of language (pp. 133-156). New York: Wiley.

Sander, L. W. (1985). Toward a logic of organization in psycho-biological development. In K. Klar \& L. Siever 


\section{Therapy}

(Eds.), Biologic response styles: Clinical implications (pp. 20-36). Washington D.C.: Monographs of the American Psychiatric Association.

Sander, L. W. (1991). Recognition process: Specificity and organization in early human development. Paper presented at the University of Massachusetts conference, The Psychic Life of the Infant.

Sander, L. W. (1995). Identity and the experience of specificity in a process of recognition: Commentary on Seligman and Shanok. Psychoanalytic Dialogues, 5(4), 579-593.

Sander, L. W. (2002). Thinking differently. Psychoanalytic Dialogues, 12(1), 11-42.

Schön, D. A. (1983). The Reflective practitioner: How professionals think in action. New York: Basic Books.

Seligman, S. (2005). Dynamic systems theories as a metaframework for psychoanalysis. Psychoanalytic Dialogues, 15(2), 285-319.

Seligman, S. (2007). Technique as a case-specific problem. Reply to commentaries. Psychoanalytic Dialogues, 17(3), 375-383.

Senge, P. M. (1990). The Fifth discipline: The art and practice of the learning organization. New York: Currency Doubleday.

Senge, P. M., Kleiner, A., Roberts, C., Ross, R., Roth, G., \& Smith, B. (1999). The dance of change: Mastering the twelve challenges to change in a learning organization. New York: Doubleday.

Senge, P. M., Kleiner, A., Roberts, C., Ross, R., \& Smith, B. (1994). The fifth discipline fieldbook. London: Nicholas Brealey Publishing.

Stacey, R. D. (2003). Complexity and group processes: A radically social understanding of individuals. Hove, U.K.: Brunner-Routledge.

Stanovich, K. E., \& West, R. F. (2000). Individual differences in reasoning: Implications for the rationality debate? Behavioral and brain sciences, 23, 645-726.

Stern, D. N. (1985). The interpersonal world of the human infant. New York: Basic Books.

Stern, D. N. (2004). The present moment in psychotherapy and everyday life. New York: Norton.

Stern, D. N., Sander, L. W., Nahum, J. P., Harrison, A. M., Lyons-Ruth, K., \& Morgan, A. C. (1998). Non interpretative mechanisms in psychoanalytic therapy: the "something more" than interpretation. International Journal of Psycho-Analysis, 79, 903-21.

Stern, S. (2009). The dialectic of empathy and freedom. International Journal of Psychoanalytic Self Psychology, 4(2), 132-164.

Stolorow, R. D. (1997). Dynamic, dyadic, intersubjective systems: An evolving paradigm for psychoanalysis. Psychoanalytic Psychology, 14(3), 337-346.

Stolorow, R. D. (1998). Clarifying the intersubjective perspective: A reply to George Frank. Psychoanalytic Psychology, 15(3), 424-427.

Stolorow, R. D., \& Atwood, G. E. (1992). Contexts of being: The intersubjective foundations of psychological life. Hillsdale, NJ.: The Analytic Press.

Stolorow, R. D., Atwood, G. E., \& Orange, D. M. (2002). Worlds of experience: Interweaving philosophical and clinical dimensions in psychoanalysis. New York: Basic Books.

Symington, N. (1983). The analyst's act of freedom as agent of therapeutic change. International Review of Psychoanalysis, 10, 283-291.

Thelen, E. (2005). Dynamic systems theory and the complexity of change. Psychoanalytic Dialogues, 15(2), 255283.

Thelen, E., \& Smith, L. B. (1994). A dynamic systems approach to the development of cognition and action. Cambridge, Mass.: MIT Press.

Trevarthen, C. (2008). The musical art of infant conversation: Narrating in the time of sympathetic experience, without rational interpretation, before words. Musicae Scientiae, Special Issue, 15-46.

Waldron, S., Scharf, R., Crouse, J., Firestein, S. K., Burton, A., \& Hurst, D. (2004). Saying the right thing at the right time: A view through the lens of the Analytic Process Scales (APS). Psychoanalytic Quarterly, 73(4), 1079-1125.

\section{Frank Martela, M.Sc.}


P.O.Box 5500

Work Psychology and Leadership

Aalto University, 02015 TKK

Finland

frank.martela@tkk.fi 